\title{
A novel and inexpensive model for practicing upper gastrointestinal endoscopy and percuta- neous endoscopic gastrostomy techniques
}

Percutaneous endoscopic gastrostomy (PEG) [1] has gained a substantial role in nutritional therapy. As the number of PEG insertions is rapidly rising worldwide, PEG has become a frequent indication for upper gastrointestinal endoscopy [2]. In order to keep the complication rates of both PEG and gastroscopy as low as possible, a structured training program involving practice in the procedures is mandatory $[3,4]$. Sophisticated endoscopic simulators are available for practice, but their high cost limits their widespread use. An inexpensive, but realistic and easily produced mechanical model was developed by the authors to acquire and refine different endoscopic techniques and percutaneous endoscopic gastrostomy insertions ( $\bullet$ Fig. 1,2). Various endoscopic maneuvers such as handling the endoscopic controls, steering the scope in different directions, retroflexion, insufflation, lavage, and suctioning can be practiced. After apposition of the "stomach" to the "abdominal wall", most of the steps of PEG can be practiced realistically and repeatedly on the same model.

Endoscopy_UCTN_Code_TTT_1AU_2AB

L. Lujber ${ }^{1}$, I. Gerlinger ${ }^{1}$, G. Fábián ${ }^{2}$, I. Szanyi ${ }^{1}$, I. Telegdy ${ }^{3}$, J.Pytel ${ }^{1}$

1 Department of Otorhinolaryngology and Head and Neck Surgery, Medical School, University of Pécs, Hungary

2 Department of Internal Medicine, Medical School, University of Pécs, Hungary

3 Department of Rheumatology, Town Hospital, Szigetvár, Hungary

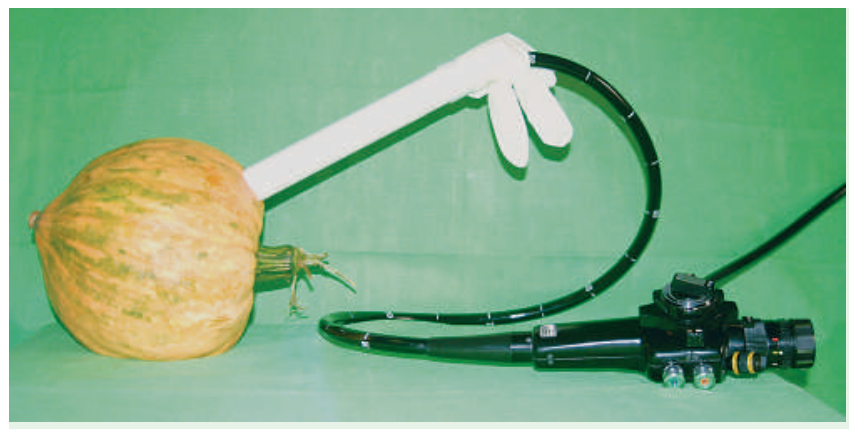

Fig. 1 A pumpkin was cut and the soft pulpy content spooned out to create a hollow structure mimicking the abdominal cavity.

With the cut surface facing down, a 2-cm-wide hole was made in the top of the pumpkin and a rigid PVC tube approximately $40 \mathrm{~cm}$ long and $2 \mathrm{~cm}$ wide was fitted into it to imitate the esophagus.

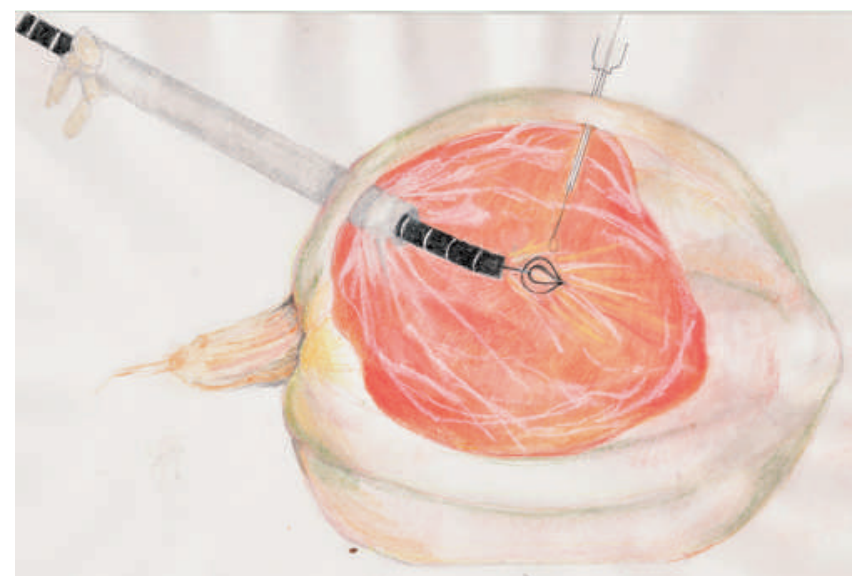

Fig. 2 With a rubber ring, an ordinary oven bag (roughly equal in size to the cavity in the pumpkin) was sealed in an airtight manner to the end of the PVC tube. A surgical glove was pulled onto and taped to the other end of the PVC tube to prevent any air leak during the gastroscopic insufflation.

The esophagogastroscope was introduced through a hole cut in the surgical glove and was advanced through the PVC tube (esophagus) into the oven bag (stomach).

\section{References}

1 Gauderer MW, Ponsky JL, Izant RJ. Gastrostomy without laparotomy: a percutaneous endoscopic technique. J Pediatr Surg 1980; 15: $872-875$

2 Lewis BS. Perform PEJ, not PED. Gastrointest Endosc 1990; 36: 311- 313

3 Ferlitsch A, Glauninger P, Gupper A et al. Evaluation of a virtual endoscopy simulator for training in gastrointestinal endoscopy. Endoscopy 2002; 34: 698-702

4 Lowe JB, Page CP, Schwesinger WH et al. Percutaneous endoscopic gastrostomy tube placement in a surgical training program. Am J Surg 1997; 174: 624-627
Bibliography

DOI 10.1055/s-2007-995494

Endoscopy 2008; 40: E73

(c) Georg Thieme Verlag KG Stuttgart · New York . ISSN 0013-726X

\section{Corresponding author}

\section{Lujber, MD, PhD}

Department of Otorhinolaryngology and

Head and Neck Surgery

Pécs University Medical School

Munkácsy M. str. 2

Pécs

Hungary $\mathrm{H}-7621$

Fax: + 36-72-228119

Lujber@yahoo.com 